\title{
LIMITACIONES TERRITORIALES Y MEDIOAMBIENTALES AL TURISMO: CAPACIDAD DE CARGA Y CAPACIDAD DE ACOGIDA $^{1}$
}

\section{TERRITORIAL AND ENVIRONMENTAL LIMITATIONS TO TOURISM: LOADING CAPACITY AND CAPACITY OF HOSPITALITY}

\author{
FELIO JOSÉ BAUZÁ MARTORELL ${ }^{2}$ \\ Universidad de las Islas Baleares
}

\section{Resumen}

La masificación del turismo -consecuencia del abaratamiento de los medios de transporte, de la economía colaborativa, de la aplicación de las tecnologías de la información y las comunicaciones al turismo...- genera no pocos problemas de seguridad, medio ambientales, de recursos (suministro de agua potable y energía eléctrica, generación de residuos...).

Este fenómeno obliga a las Administraciones Públicas, en función de sus distintas competencias, a reconsiderar su intervención administrativa y limitar el acceso a determinados espacios y enclaves, debidamente justificados, con fórmulas diversas, desde la tributación hasta la restricción directa de la movilidad. Esta limitación de acceso al dominio público plantea problemas de índole jurídica por la restricción que opera sobre el uso público general de estos bienes públicos.

Palabras Clave: Turismo, territorio, medio ambiente, capacidad de carga, capacidad de acogida, tasa turística.

\section{Abstract}

The massification of tourism -consequence of the cheapening of means of transport, of the collaborative economy, of the application of information technologies and communications to tourism ... - generates many security, environmental and resource problems (supply of drinking water and electricity, generation of waste ...).

\footnotetext{
${ }^{1}$ Artículo redactado en el marco del proyecto de investigación "Big data, cloud computing y otros nuevos retos jurídicos planteados por las tecnologías emergentes, en particular, su incidencia en el sector turístico" (DER2015-63595-R).

${ }^{2}$ fj.bauza@uib.es. El autor pertenece al Cuerpo Superior de Administradores Civiles del Estado, es Doctor en Derecho, Consejero del Consejo Consultivo de Baleares, vocal permanente de la Comisión General de Codificación del Ministerio de Justicia y académico correspondiente de la Real Academia de Jurisprudencia y Legislación. Es profesor Contratado Doctor (acreditado para el Cuerpo de Profesores Titulares de Universidad) de la Universidad de las Islas Baleares.
} 
This phenomenon obliges the Public Administrations, depending on their different competences, to reconsider their administrative intervention and limit access to certain spaces and enclaves, duly justified, with different formulas, from taxation to direct restriction of mobility. This limitation of access to the public domain raises problems of a legal nature due to the restriction that operates on the general public use of these public goods.

Key words: Tourism, territory, environment, carrying capacity, capacity of reception, tourist tax.

Fecha de recepción: 21 de marzo de 2019 Fecha de aprobación: 19 de mayo de 2019

\section{PLANTEAMIENTO.}

Siendo como es el turismo uno de los principales motores de la economía mundial, las políticas públicas en esta materia tradicionalmente han consistido en el fomento del mismo a través de actividades de promoción (participación en ferias internacionales, campañas publicitarias, patrocinio institucional...), planes de modernización de la planta hotelera, programas de desestacionalización y diversificación de la oferta turística, políticas de infraestructuras... y un largo etcétera.

Sin embargo, las últimas temporadas estivales han permitido constatar un turismo de masas, que colapsa fundamentalmente los núcleos de las ciudades, con evidentes repercusiones para la población residente: por un lado el turismo estimula el comercio y la oferta complementaria, si bien por otro afecta al consumo de recursos energéticos e hidrológicos, encarece el precio de la vivienda para los vecinos, y hasta plantea problemas de orden público.

Paradójicamente la estadística permite apreciar que las estancias hoteleras disminuyen frente al número de visitas, que aumenta. Esto significa que el turismo aumenta por canales ajenos al tradicional alojamiento hotelero, fundamentalmente a través de la vivienda turística vacacional.

En consecuencia un nuevo modelo turístico está desplazando el esquema convencional de sol y playa, y de temporada estival. Por el contrario, los portales de internet han contribuido a crear este nuevo modelo, que ha venido para quedarse.

Otra cosa es que el turismo de masas, que en gran medida propicia la vivienda vacacional, y el fenómeno conocido con el anglicismo de la gentrificación, conlleve desafíos de todo tipo: urbanísticos (superposición de usos residenciales y terciarios sobre un mismo suelo ${ }^{3}$ ), sociales (contaminación acústica, turismo fobia), saturación de infraestructuras viarias y zonas de aparcamiento, generación de residuos, presión ambiental sobre el territorio... hasta el punto de que las políticas públicas a día de hoy en materia de turismo comiencen a apuntar hacia la restricción de la población visitante.

3 BAUZÁ MARTORELL, F. J. <<Planeamiento urbanístico y turismo. A propósito de la zonificación del alquiler turística >> Práctica Urbanística núm. $\mathrm{n}^{\circ}$ 152, mayo-junio 2018, № 152 , 1 de mayo de 2018, Editorial Wolters Kluwer. SOCÍAS CAMACHO, J. <<Un problema actual de la vivienda: uso residencial versus uso turístico>> Revista de Derecho Urbanístico y medio ambiente núm. 317. Noviembre 2017, pp. 17-47. 
La masificación turística no es exclusiva de España y no en vano en nuestro entorno pueden apreciarse iniciativas normativas consistentes en la limitación de turistas. El caso más llamativo es el de Venecia, que acusa un daño ambiental y social que retrata el documental El síndrome de Venecia (2015). Con una población de apenas cincuenta mil habitantes (a mediados del siglo XX superaba los dos cientos mil), la ciudad recibe entre veinticinco y treinta millones de visitantes al año como consecuencia fundamentalmente del turismo de cruceros. Por ello la ciudad de Venecia, junto a la tasa turística, ha adoptado una tasa de entrada para las estancias sin pernoctación (tasa de desembarco), como también cuenta desde el Decreto de Alcaldía de 24 de abril de 2018 con cinco tornos que cierran la entrada de visitantes cuando alcanza un determinado número, como también prohíbe la apertura de negocios de comida rápida en la calle con la excepción de heladerías. En Dubrovnik por otro lado se limita el atraque de cruceros y se han retirado terrazas de cafeterías y puestos de recuerdos de las calles. En Amsterdam se prohíbe la concesión de autorizaciones de comercios para turistas en los barrios más visitados.

En efecto recientemente las políticas sectoriales de turismo -especialmente en territorios insulares- apuntan hacia otra dirección: la limitación de turistas, ya sea a través de la zonificación del alquiler turístico, o la instalación de tornos a determinadas áreas como el casco antiguo de las ciudades; la restricción de vehículos de alquiler; la prohibición de que atraquen en puerto un número de cruceros superior al permitido; la instauración y/o incremento de impuestos de estancias turísticas...

Todas estas medidas se adoptan por motivos medio ambientales y territoriales, y en consecuencia deben ampararse en una fundamentación jurídica suficiente, porque de lo contrario pueden contradecir el principio general de libertad de movimientos por todo el territorio nacional (art. $19 \mathrm{CE}$ ), la libertad de empresa en el marco de la economía de mercado (art. $38 \mathrm{CE}$ ), o la libre circulación de personas (art. 45 TFCE), entre otros.

En consecuencia en las páginas que siguen, se pretende analizar esta problemática desde la óptica social y política de la dimensión del turismo, y muy especialmente desde la vertiente jurídica.

Así, nos planteamos analizar desde una perspectiva legal los conceptos de capacidad de carga -que urbanísticamente afectan a un territorio a la hora de planificar su desarrollo-, como también el principio de capacidad de acogida, que se traduce en el análisis de los recursos de que dispone un territorio -en este caso, un territorio turísticopara verificar qué parámetros son los que afectan al crecimiento de la población residente y visitante. Por último haríamos especial hincapié en las posibilidades jurídicas de limitar el número de turistas, analizando por ello normativa comunitaria, estatal y autonómica.

\section{CAPACIDAD DE CARGA Y CAPACIDAD DE ACOGIDA.}

Con carácter general en urbanismo y ordenación del territorio la capacidad de carga se define como el número potencial de personas que un determinado espacio o lugar puede albergar, en función de parámetros urbanísticos, ambientales, paisajísticos, infraestructuras... 
Las distintas leyes autonómicas del suelo $^{4}$ y su normativa complementaria vienen introduciendo parámetros e indicadores en materia de capacidad de carga, como límite general al territorio. Los indicadores particulares en materia turística forman parte de este concepto de capacidad de carga, y persiguen una armonización de la densidad de población residencial con la población visitante, en consonancia a su vez con vectores medio ambientales y la disponibilidad de recursos (agua potable, energía eléctrica y gas, recogida de residuos... $)^{5}$.

La ordenación del territorio se concibe en las distintas Comunidades Autónomas mediante planes territoriales generales y planes directores sectoriales. Entre estos últimos los planes en materia de turismo establecen la capacidad de carga y los límites máximos de la población visitante. En consecuencia una primera limitación del turismo pasa por estos planes directores sectoriales ${ }^{6}$.

\section{1.- Canarias.}

Los territorios insulares son especialmente sensibles a esta problemática, por cuanto combinan la afluencia turística y las limitaciones territoriales. En el caso de Canarias la Ley 19/2003, de 14 de abril, por la que se aprueban las Directrices de Ordenación General y las Directrices de Ordenación del Turismo de Canarias, contempla de manera expresa la normativa de las directrices de ordenación del turismo de Canarias, en cuyo Capítulo IV regula las condiciones de crecimiento.

Entre los objetivos de estas limitaciones o restricciones, la Directriz 24 justifica el crecimiento selectivo a partir de la creación de nuevos productos cualificados, que diversifiquen la oferta, y que tengan la capacidad de innovar el mercado, atraer otros segmentos de demanda, competir con otros destinos, y contribuir al crecimiento de la economía local y del archipiélago.

Al mismo tiempo la Ley es muy clara a la hora de determinar que la necesidad de ordenar y dimensionar el crecimiento alojativo parte de la exigencia de reducir las afecciones ambientales y territoriales, directas e inducidas, sobre un medio frágil, así como de atemperar el crecimiento a la capacidad de absorción de la sociedad local y la disponibilidad de las infraestructuras y servicios, y de atender al carácter estratégico y prioritario que las presentes Directrices otorgan a la renovación de la planta turística existente, por su mayor grado de sostenibilidad, en tanto que constituye una reutilización eficiente del patrimonio urbano e inmobiliario existentes.

A continuación la Directriz 25 se refiere de manera expresa a la capacidad de carga y entiende que toda decisión de transformación por la urbanización del suelo con destino turístico requiere ser establecida y fundamentada técnicamente en la capacidad de carga de la zona turística afectada, entendida como el conjunto de factores que

\footnotetext{
${ }^{4}$ Sobre los efectos de la Sentencia del Tribunal Constitucional 61/1997, vid. FERNÁNDEZ, T. R. $<<$ El desconcertante presente y el imprevisible y preocupante futuro del Derecho urbanístico español $>>$ Revista Española de Derecho Administrativo núm. 94. 1997, pp. 189-201.

${ }^{5}$ Sobre la capacidad de carga en materia urbanística y turística, vid. SALOM PARETS, A. $<<$ La capacidad de carga “conditio iuris" en la normativa territorial y turística $>>$ Revista de Derecho Urbanístico y medio ambiente núm. 313. Abril-mayo 2017, pp. 39-63.

${ }^{6}$ BLASCO ESTEVE, A. <<La planificación territorial de las zonas turísticas en España $>>$ Revista de Derecho Urbanístico y medio ambiente núm. 262. Diciembre 2010. BOUAZZA ARIÑO, O. BASSOLS COMÀ, M. Planificación turística autonómica. Reus. Barcelona, 2007.
} 
permiten el uso turístico de una zona sin un declive inaceptable de la experiencia obtenida por los visitantes, una excesiva presión sobre los recursos turísticos de la misma, una alteración ecológica sobre la sociedad residente, y disponiendo de los equipamientos, servicios e infraestructuras generales precisos para el desarrollo de la actividad y de la población de servicios que demande. Esta capacidad habrá de ser considerada y analizada por el planeamiento urbanístico en cuanto factor determinante de la sectorización la sectorización de suelo con destino turístico. Todo ello bajo los criterios de capacidad global de carga turística y los criterios específicos determinados por el planeamiento insular.

La determinación de la capacidad de carga integra un documento autónomo dentro de los instrumentos de planeamiento, y se fundamenta, al menos, en los siguientes factores relevantes:

a) Capacidad ecológica, que identificará y valorará los cambios que previsiblemente haya de producir en los ecosistemas la implantación de la actividad turística de que se trate.

b) Capacidad social, que analizará los efectos sobre la población residente, sobre sus condiciones urbanas, habitacionales, de mercado de trabajo y de entorno cultural, así como su afección a los servicios educativos, sanitarios y de bienestar social disponibles.

c) Capacidad paisajística, definida como la potencialidad del paisaje para asumir las actuaciones previstas sin alteración de sus rasgos y elementos característicos.

d) Capacidad de las infraestructuras de accesibilidad y otras existentes para atender el funcionamiento y abastecimiento del ámbito, y posibilidad de absorción de los impactos que se deduzcan de la dotación o ampliación de dichas infraestructuras.

e) Capacidad del mercado, considerando el crecimiento potencial de la demanda frente a la nueva oferta, con el fin de evitar que la generación de desequilibrios entre oferta y demanda deteriore la competitividad del destino y de los operadores.

f) Disponibilidad de recursos tecnológicos, profesionales y laborales necesarios para las fases de construcción y explotación de los establecimientos turísticos que se prevean, estimada bajo la hipótesis de aplicar medidas y sistemas adecuados a la conservación del medio ambiente, el ahorro de energía y de agua, y la correcta gestión de los residuos.

g) Disponibilidad de recursos turísticos, evaluados en relación con los productos turísticos previstos, fundamentada en un inventario valorado, destinado a estimar la orientación turística del ámbito y la correspondencia entre recursos, productos turísticos, tipo de demanda y actividades turísticas propuestas.

h) Afección a recursos naturales existentes en los ámbitos propuestos para la actividad urbanística, y en su entorno de influencia ambiental, paisajística y funcional, fundamentada en un inventario y valoración de los recursos y en la previsión de las medidas para su conservación.

Para la valoración de los recursos naturales implicados en la actuación, se considerarán en todo caso como elementos sensibles, los siguientes: 
1) Los espacios litorales, cuya extensión a este efecto de protección se establece como la franja costera de 500 metros de anchura, medida desde la ribera del mar.

2) Los relieves y horizontes definidores de los paisajes característicos de cada isla.

3) Las formaciones orográficas y escenográficas naturales características, como los acantilados, barrancos, lomos, conos volcánicos y calderas, entre otras. territorio.

4) Los suelos agrícolas productivos, y los que caracterizan la imagen del

5) La vegetación y, especialmente, el arbolado.

Por último y de manera concreta en materia de límites del crecimiento, la Directriz 26 se refiere a los instrumentos de planeamiento municipal, a los que permite igualmente introducir restricciones al crecimiento turístico. Así, la Norma obliga al planeamiento insular a declarar agotada la capacidad de carga de aquellos ámbitos territoriales en los que así se deduzca del análisis de los factores relacionados en la Directriz anterior, pudiendo afectar dicha declaración a zonas o núcleos concretos de una isla o a la totalidad de la misma. Los efectos de la declaración serán los siguientes:

a) En el ámbito declarado, no podrá aumentar el número de plazas turísticas sobre la oferta existente.

b) En las zonas turísticas incluidas dentro del ámbito declarado, no podrá aumentar el número de plazas residenciales, salvo expresa previsión en contrario del plan insular, debidamente justificada.

En particular, el planeamiento insular debe justificar la previsión de crecimiento alojativo turístico que el mismo establezca, en relación con la existencia material o dotación financiera para la ejecución de infraestructuras y servicios generales suficientes para cubrir las necesidades de la población residente y turista existentes, como de la generada por el crecimiento turístico previsto, requiriéndose informe de las administraciones competentes. En todo caso, la disponibilidad y capacidad de los servicios de sanidad y educación públicas para el incremento de demanda previsto, será un factor limitante para su desarrollo.

\section{2.- Baleares.}

En las Islas Balares la ordenación del territorio turístico se ha llevado a cabo a través del plan director sectorial de ordenación de la oferta turística (POOT), aprobado en la isla de Mallorca por Decreto 54/1995, de 6 de abril. El objetivo básico del POOT fue el de fijar un techo máximo de plazas de alojamiento hotelero en cada uno de los sectores o zonas en que dividía la isla de Mallorca.

La vigente Ley 8/2012, de 19 de julio, del Turismo de las Islas Baleares, deroga el POOT y contempla otro instrumento de ordenación del territorio en materia turística, cual es el Plan de Intervención en Ámbitos Turísticos (PIAT).

En este sentido el art. 5 de la Ley define los PIATs como planes directores sectoriales cuyo objeto es el de regular el planeamiento, la ejecución y la gestión de los sistemas generales de las infraestructuras, los equipamientos, los servicios y las actividades de explotación de recursos en el ámbito de la ordenación turística. Su 
ámbito espacial o físico es insular, de manera que la Administración competente para su aprobación es el pleno del Consejo insular respectivo.

La Ley permite a los PIATs establecer la densidad global máxima de población, delimitar zonas y ámbitos turísticos y de protección, y fijar el tamaño y las características, así como establecer parámetros mínimos o máximos de superficie, volumetría, edificabilidad y equipamientos. También pueden delimitar las zonas turísticas saturadas o maduras, de acuerdo con los criterios establecidos en esta ley. Y asimismo, pueden señalar las excepciones que por la ubicación o las características especiales así lo aconsejen. Igualmente, les permite determinar estos parámetros respecto a las zonas residenciales lindantes con las turísticas.

Asimismo, los PIAT y, si procede, los Planes Territoriales Insulares (PTI), tienen que analizar, con respecto a cada una de las zonas, la incidencia de los establecimientos con pensión integral. Estos instrumentos de ordenación territorial tienen que establecer los criterios para la delimitación de las zonas aptas para la comercialización de estancias turísticas en viviendas de uso residencial. Sobre la base de estos criterios, los ayuntamientos tienen que implantar las zonas aptas para la comercialización de estancias turísticas en viviendas residenciales incorporando la delimitación al planeamiento urbanístico respectivo mediante la correspondiente documentación cartográfica. Esta delimitación cartográfica no será considerada una modificación estructural del planeamiento.

Los PIAT y, si procede, los PTI pueden determinar también el límite máximo por isla de plazas turísticas en alojamientos turísticos y el límite máximo de plazas en viviendas residenciales susceptibles de ser comercializadas turísticamente, en función de los recursos insulares existentes, las infraestructuras, las densidades de población y otros parámetros relevantes de su ámbito. En este supuesto, las bolsas de plazas se tienen que adaptar a esta cifra.

Hasta que no se determine esta cifra o si no se considera necesario determinarla, el techo máximo de plazas por isla tiene que ser el determinado por las existentes legalmente más las que integren las bolsas gestionadas por los organismos gestores de plazas turísticas o las administraciones turísticas insulares, con las especificaciones previstas para la isla de Menorca ${ }^{7}$.

Los PIAT y, en su caso, los PTI pueden determinar la existencia de dos bolsas de plazas: una relativa a alojamientos turísticos y la otra relativa a estancias turísticas en viviendas residenciales. Desde este momento las bolsas existentes se tienen que distribuir en el sentido indicado. Durante este período solamente existirá una bolsa de plazas común tanto para los alojamientos turísticos como para las estancias turísticas en viviendas residenciales.

${ }^{7}$ Estas excepciones se hallan previstas en el art. 89 de la Ley 8/2012: Mientras el PIAT o, si procede, el PTI de la isla de Menorca no determine el techo máximo de plazas, las viviendas objeto de comercialización de estancias turísticas, los establecimientos de alojamiento de turismo rural, los de turismo de interior, los hoteles ciudad, las hospederías y los establecimientos de alojamiento ubicados en las zonas turísticas de la isla que se determinan en las normas de ordenación territorial correspondientes, tienen que continuar excluidos de lo que dispone el artículo 88 anterior, relativo a la baja definitiva como requisito para el inicio de una actividad turística, y de lo que dispone el artículo 5.3, ambos de esta ley, en cuanto al techo máximo por isla. 
A día de hoy en Baleares el Consejo Insular de Mallorca ha aprobado provisionalmente el PIAT, mientras que el Consejo Insular de Menorca aprobó definitivamente el PIAT mediante acuerdo de pleno de fecha 16 de julio de 2018. Ni el Consejo Insular de Ibiza ni el de Formentera han aprobado PIAT alguno.

En este nivel aparece el concepto de capacidad de acogida, que afectan al parque de viviendas de un espacio o lugar, las infraestructuras existentes y las proyectadas, los equipamientos urbanos, espacios recreativos, zonas verdes...

En este sentido y mientras las normas analizadas hasta el momento se refieren a grandes principios, por el contrario la elaboración de los instrumentos de ordenación del territorio y los de planeamiento urbanístico sí deben tener en cuenta la capacidad de acogida, porque vinculan los límites del crecimiento a las necesidades físicas existentes. En consecuencia esta realidad es la que motiva y justifica en última instancia las restricciones al crecimiento de la población turística.

\section{3.- Andalucía.}

En la misma línea de la limitación al crecimiento de la población visitante y sin perjuicio de los instrumentos de ordenación del territorio en Andalucía que prevén la sostenibilidad con carácter general (y también turística ${ }^{8}$ ), esta Comunidad Autónoma cuenta con los programas de recualificación turística con el objeto de replantear un modelo turístico basado en el crecimiento ${ }^{9}$.

En efecto en materia de ordenación del territorio tanto el Plan de Ordenación del Territorio de Andalucía (Norma 45) cono los planes de ámbito subregional contienen medidas tendentes a adecuar el crecimiento poblacional a un mínimo consumo de los recursos naturales, siendo obligado mencionar en este punto el Plan de Ordenación del Territorio de la Aglomeración Urbana de Granada (1999).

Adicionalmente y desde la perspectiva sectorial, la ordenación de los recursos turísticos en Andalucía se aborda desde 206 con el Plan de Recualificación Turística de la Costa del Sol Occidental, el Plan Qualifica.

Este Plan, que comprende los municipios de Torremolinos, Benalmádena, Fuengirola, Mijas, Marbella, Estepona, Casares y Manilva, se plantea entre sus objetivos el aumento de la calidad y de la competitividad del destino Costa del Sol, mediante el diseño de estrategias basadas en la rehabilitación cualitativa del patrimonio y del espacio turístico, bajo las premisas de sostenibilidad y rentabilidad socioeconómica, apostando por la diferenciación frente a la estandarización.

En tanto que acuerdo entre la Junta de Andalucía y agentes empresariales, sociales e institucionales, el Plan Qualifica es el resultado de la directa colaboración entre el sector público y el sector privado, así como un paso más en la vinculación entre planificación y gestión. Al decir de la doctrina más autorizada, no es sólo un elemento

8 ZAMORA ROSELLÓ, M. R. <<La sostenibilidad turística a través de los instrumentos andaluces de planificación>>> Revista Andaluza de Administración Pública núm. 98, 2017, pp. 395-426.

${ }^{9}$ NAVARRO JURADO, E. ¿Puede seguir creciendo la Costa del Sol? Indicadores de saturación de un destino turístico, Colección Monografías, Servicio de Publicaciones de la Diputación de Málaga, 2003. 
de reconversión y recualificación de la Costa del Sol Occidental, sino una figura de planeamiento con incidencia más allá de la provincia de Málaga ${ }^{10}$.

\section{III.- MEDIDAS TRIBUTARIAS DISUASORIAS.}

La tributación de la estancia turística es un medio efectivamente disuasorio para la visita de espacios turísticos. En la teoría económica los precios siempre han sido un factor corrector de la demanda ${ }^{11}$.

No en vano el "Estudio sobre la regulación de las viviendas de uso turístico en España”, elaborado por la CNMC en fecha 19 de julio de 2018, a la hora de valorar las restricciones por zonas o barrios a las viviendas de uso turístico, considera expresamente que "un instrumento más proporcionado y menos distorsionador de la competencia que la zonificación para internalizar el coste de las externalidades negativas derivadas de la congestión en algunas zonas sería la intervención mediante un impuesto o tasa sobre la estancia en alojamientos turísticos, sin diferenciación del tipo de alojamiento" ${ }^{\prime 2}$.

En España sólo dos Comunidades Autónomas han hecho acopio de este tributo: Baleares y Cataluña.

\section{1.- Baleares.}

\section{A.- Antecedentes normativos.}

Baleares fue la Comunidad pionera en esta regulación, con la Ley 7/2001 de 23 de abril, del impuesto sobre las estancias en empresas turísticas de alojamiento, destinado a la dotación del fondo para la mejora de la actividad turística y la preservación del medio ambiente ${ }^{13}$.

Con ocasión de la creación del tributo, se debatió la forma de recaudación del mismo, planteándose la posibilidad de que se recabara en puertos y aeropuertos, si bien finalmente acabó gravando la estancia en establecimientos de alojamiento hotelero y extra hotelero.

En desarrollo de la Ley 7/2001 el Consejo de Gobierno de Baleares aprobó el Decreto 26/2002, de 22 de febrero, por el que se desarrolla la Ley 7/2001, de 23 de abril, del impuesto sobre las estancias en empresas turísticas de alojamiento, destinado a la dotación del fondo para la mejora de la actividad turística y la preservación del medio ambiente. Igualmente se dictaron tres Órdenes de la Consejería de Hacienda y Presupuestos, de fechas 3 de abril de 2002: Orden por la que se regula la determinación

${ }^{10}$ ZAMORA ROSELLO, M. R. “La Ordenación de los recursos turísticos”, en FWERNÁNDEZ RAMOS, S. - PÉREZ MONGUIÓ, J. M. - PRADOS PRADOS, S. Estudios sobre el derecho andaluz del turismo. Junta de Andalucía. Sevilla, 2008, p. 165.

${ }^{11}$ Sobre fiscalidad y turismo, vid. GARCÍA CALVENTE, Y. "Régimen tributario del turismo colaborativo” en GOSÁLBER PEQUEÑO, H. (Dir.) El régimen jurídico del turismo colaborativo. Wolters Kluwer. Madrid, 2019.

${ }^{12}$ E/CNMC/003/18 Estudio sobre la regulación de las viviendas de uso turístico en España. 19 de julio de 2018.

${ }^{13}$ BOIB núm. 52 de 01 de Mayo de 2001 y BOE núm. 125 de 25 de Mayo de 2001. 
de la base imponible y la gestión del Impuesto; Orden por la que se regulan las declaraciones censales de comienzo, modificación o cese de actividad a presentar por los sustitutos del contribuyente; y, Orden por la que se aprueban los requisitos formales, contenido y plazos para las anotaciones registrales en cada uno de los Libros Registros que debe llevar el sustituto del contribuyente.

En 2001 la creación de un tributo al turismo fue recibido con enorme contestación social y empresarial del sector hotelero. Por un lado, la Ley fue objeto de recurso de inconstitucionalidad ante el Tribunal Constitucional, número 4407-2001, promovido por el Abogado del Estado, en representación del Presidente del Gobierno, con invocación del artículo 161.2 de la Constitución ${ }^{14}$.

A mayor abundamiento en sede judicial se planteó la doble imposición entre el tributo turístico y el IVA, dado que ambos podían estar gravando el mismo hecho imponible, cual es la prestación de servicios turísticos. Sin embargo el Tribunal Superior de Justicia de Baleares desestimó la doble imposición en diferentes pronunciamientos $^{15}$.

Con ocasión de un cambio de gobierno, la Ley 7/2001 fue derogada por la Ley 7/2003, de 22 de octubre.

\section{B.- Derecho vigente.}

La regulación vigente del tributo a día de hoy se concreta en la Ley 2/2016, de 30 de marzo, del Impuesto sobre estancias turísticas en las Illes Balears, y de medidas de impulso del turismo sostenible. La Ley fue desarrollada por el Decreto 35/2016, de 23 de junio, por el que se desarrolla la Ley del impuesto sobre estancias turísticas y de medidas de impulso del turismo sostenible.

La Ley 2/2016 configura el hecho imponible del tributo las estancias, por días o fracciones, con o sin pernoctación, que los contribuyentes realicen en las Illes Balears en los siguientes establecimientos turísticos:

a) Los establecimientos de alojamiento hotelero, eso es, los hoteles, los hoteles de ciudad, los hoteles apartamentos y los alojamientos de turismo de interior.

b) Los apartamentos turísticos.

c) Las diversas clases de alojamientos de turismo rural, eso es, los hoteles rurales y los agroturismos.

d) Los albergues y los refugios.

\footnotetext{
${ }^{14}$ B.O.E número 236, de 2 de octubre de 2001.

${ }^{15}$ Sentencia del TSJ de Islas Baleares, (Sala de lo Contencioso Administrativo, núm. 288/2006 de 21 marzo, (rec. 102/2004); Sentencia del TSJ de Islas Baleares, (Sala de lo Contencioso Administrativo, núm. 486/2006, de 19 de mayo, (rec. 431/2002); Sentencia del TSJ de Islas Baleares, Sala de lo Contencioso administrativo, 464/2007 de 28 de mayo de 2007, (rec. 18/2007); Sentencia del TSJ de Islas Baleares, Sala de lo Contencioso administrativo, 544/2008 de 29 de septiembre de 2008, (rec. 149/2007); Sentencia del TSJ de Islas Baleares, Sala de lo Contencioso Administrativo, núm. 720/2008 de 9 diciembre (rec. 29/2007); Sentencia del TSJ de Islas Baleares, Sala de lo Contencioso Administrativo, núm. 130/2009 de 25 febrero, (rec. núm. 970/2005); Sentencia del TSJ de Islas Baleares, Sala de lo Contencioso Administrativo, núm. 351/2009 de 5 mayo, (rec. núm. 150/2007).
} 
e) Las hospederías.

f) Los establecimientos explotados por las empresas turístico-residenciales, excepto con respecto a las unidades de alojamiento residencial.

g) Los hostales, los hostales-residencia, las pensiones, las posadas, las casas de huéspedes y los campamentos de turismo o campings.

h) Las viviendas turísticas de vacaciones, las viviendas objeto de comercialización de estancias turísticas y las viviendas objeto de comercialización turística susceptibles de inscripción de acuerdo con las leyes que las regulan.

i) El resto de establecimientos y viviendas a los que la normativa autonómica otorga la calificación de turísticos.

j) Las viviendas objeto de comercialización turística que no cumplan con los requisitos establecidos para ello en la normativa autonómica y que, por lo tanto, no sean susceptibles de inscripción de acuerdo con la legislación turística vigente.

k) Las embarcaciones de crucero turístico cuando realicen escala en un puerto de las Illes Balears. De acuerdo con ello, no se incluyen los inicios ni las llegadas de los cruceros con salida o destino final en las Illes Balears.

Entre las principales novedades de la regulación que opera esta ley consiste en la inclusión en el hecho imponible a los cruceros, extremo que fue objeto de requerimiento por parte de la Administración General del Estado.

Por lo demás, la disposición final tercera de la Ley 13/2017, de 29 de diciembre, de Presupuestos Generales de la Comunidad Autónoma de las Illes Balears para el año 2018, incrementa un 100 por 100 la cuota tributaria, fijándose con carácter general en los cuatro euros diarios por persona y día.

El destino de los fondos recaudados con cargo a este impuesto consiste en la preservación del medio ambiente. Así, la Ley crea el fondo para favorecer el turismo sostenible como instrumento de financiación de los proyectos que se aprueben, $\mathrm{y}$ a fin de impulsar un turismo sostenible, responsable y de calidad en el archipiélago de las Illes Balears. Este fondo se nutre de la recaudación total del impuesto sobre estancias turísticas en las Illes Balears.

Los recursos de dicho fondo se destinan a financiar, total o parcialmente, inversiones y otros gastos que, en ejecución de los proyectos que se aprueben, se destinen a las siguientes actuaciones:

a) Protección, preservación, modernización y recuperación del medio natural, rural, agrario y marino.

b) Fomento de la desestacionalización, creación y activación de productos turísticos practicables en temporada baja, y promoción del turismo sostenible y de temporada baja.

c) Recuperación y rehabilitación del patrimonio histórico y cultural. 
d) Impulso de proyectos de investigación científica, desarrollo e innovación tecnológica $(\mathrm{I}+\mathrm{D}+\mathrm{i})$ que contribuyan a la diversificación económica, la lucha contra el cambio climático o relacionados con el ámbito turístico.

e) Mejora de la formación y la calidad del empleo. Fomento de la ocupación en temporada baja.

f) Actuaciones en políticas de vivienda destinadas a fomentar el acceso a la vivienda, y especialmente el alquiler social, con criterios de sostenibilidad energética.

En el conjunto de estas actuaciones, se priorizan los proyectos de carácter medioambiental. En todo caso, los proyectos que se aprueben deben ser sostenibles desde el punto de vista ambiental, social y económico ${ }^{16}$.

\section{2.- Cataluña.}

En términos semejantes a la estructura y arquitectura del impuesto balear de 2001, el Parlamento catalán aprobó la Ley 5/2012, de 20 de marzo, de medidas fiscales, financieras y administrativas y de creación del impuesto sobre las estancias en establecimientos turísticos, cuyo título III -relativo al impuesto sobre estancias en establecimientos turísticos- fue derogado por la Ley 5/2017, 28 marzo, de medidas fiscales, administrativas, financieras y del sector público y de creación y regulación de los impuestos sobre grandes establecimientos comerciales, sobre estancias en establecimientos turísticos, sobre elementos radiotóxicos, sobre bebidas azucaradas envasadas y sobre emisiones de dióxido de carbono.

La regulación legal de este tributo fue desarrollada por el Decreto 141/2017, de 19 de septiembre, por el que se aprueba el Reglamento del impuesto sobre las estancias en establecimientos turísticos.

Para el legislador catalán la estancia en establecimientos y equipamientos turísticos pone de relieve "una singular capacidad económica” (art. 23 Ley 5/2017), que justifica el objeto del tributo.

El hecho imponible consiste en la estancia, por días o fracciones, con pernoctación o sin ella, que realizan los contribuyentes en los establecimientos y equipamientos turísticos situados en Cataluña.

En el caso de las embarcaciones de crucero turístico, se entiende realizado el hecho imponible cuando estas estén amarradas en un puerto del territorio de Cataluña. A tal efecto, se considera que el buque queda amarrado a un puerto desde el momento en que se lanza el primer cabo durante la atracada hasta el momento en que el buque afloja la última amarra.

Asimismo la Ley entiende por estancia el disfrute del servicio de alojamiento, por día o fracción, con pernoctación o sin ella.

Están sujetos al impuesto las estancias en los siguientes establecimientos y equipamientos turísticos:

\footnotetext{
${ }^{16}$ Para comprender este tributo, vid. el análisis que realiza in extenso FERNÁNDEZ GONZÁLEZ, C. El impuesto balear de estancias turísticas. Lleonard Muntaner, editor. Palma, 2017.
} 
a) Los alojamientos turísticos establecidos en cada momento por la normativa vigente en materia de turismo.

b) Los albergues de juventud, cuando presten servicios turísticos de alojamiento.

c) Las embarcaciones de crucero turístico.

d) Cualquier establecimiento o equipamiento en el que se presten servicios turísticos de alojamiento.

A los efectos de la aplicación de este impuesto, el concepto de servicios turísticos de alojamiento se refiere a los servicios que posibilitan el hospedaje en infraestructuras, instalaciones, equipamientos o mobiliarios destinados a este fin.

\section{IV.- LIMITACIÓN DEL NÚMERO DE TURISTAS.}

La masificación turística está propiciando la reacción de la intervención administrativa en forma de limitación del número de turistas que pueden acceder a determinados espacios, ya sea por razones medio ambientales o de seguridad.

En efecto las aglomeraciones de gentes es un hecho incontestable, en las que tiene mucho que ver el cambio y transformación del modelo turístico que las tecnologías han generado. En este sentido hemos pasado de un turismo ordenado, de grupos de visitantes alrededor de un guía, a una forma de turismo más libre, en la que el turista accede directamente a cualquier espacio sin necesidad de intermediario, y que no tiene por qué hospedarse exclusivamente en establecimientos hoteleros o apartamentos.

Todo ello viene explicado, como decimos, por las tecnologías de la información y las comunicaciones ${ }^{17}$, y por la economía colaborativa ${ }^{18}$.

Sea como fuere, la intervención administrativa en estos casos pasa por la limitación de vehículos en determinadas carreteras, el establecimiento de un sistema de cupos, la implantación de tornos para el acceso a determinados espacios, y todo ello con base en razones de seguridad, medio ambiente....

\section{1.- Tránsito rodado de vehículos a motor.}

\section{A.- Régimen jurídico.}

En desarrollo de la Ley de Seguridad Vial -cuyo régimen jurídico vigente a día de hoy se residencia en el Real Decreto Legislativo 6/2015, de 30 de octubre, por el que se aprueba el texto refundido de la Ley sobre Tráfico, Circulación de Vehículos a Motor y Seguridad Vial- el Real Decreto 1428/2003, de 21 de noviembre, por el que se aprueba el Reglamento General de Circulación para la aplicación y desarrollo del texto

17 BAUZÁ MARTORELL, F. J. <<Intervención administrativa en la vivienda turística vacacional >> Revista Española de Derecho Administrativo núm. 189. 2018. Págs. 313 a 346 . Del mismo autor, <<Big data y open data en la administración turística: acceso y reutilización de información>> Revista Vasca de Administración Pública núm. 108 (mayo-agosto), 2017, pp. 19-41.

${ }^{18}$ DE LA ENCARNACIÓN, A. M. <<El alojamiento colaborativo: Viviendas de uso turístico y plataformas virtuales $>>$ Revista de Estudios de la Administración Local y Autonómica núm. 5. Enerojunio 2016. 
articulado de la Ley sobre tráfico, circulación de vehículos a motor y seguridad vial, aprobado por el Real Decreto Legislativo 339/1990, de 2 de marzo, contempla con carácter general las limitaciones a la circulación y de manera específica la ordenación especial del tráfico por razones de seguridad o fluidez de la circulación.

En este sentido y de acuerdo con el art. 39 del Real Decreto 1428/2003, se permite establecer limitaciones de circulación, temporales o permanentes, en las vías objeto de la legislación sobre tráfico, circulación de vehículos a motor y seguridad vial, cuando así lo exijan las condiciones de seguridad o fluidez de la circulación.

Asimismo en determinados itinerarios, 0 en partes 0 tramos de ellos comprendidos dentro de las vías públicas interurbanas, así como en tramos urbanos, incluso travesías, se pueden establecer restricciones temporales o permanentes a la circulación de camiones con masa máxima autorizada superior a 3.500 kilogramos, furgones, conjuntos de vehículos, vehículos articulados y vehículos especiales, así como a vehículos en general que no alcancen o no les esté permitido alcanzar la velocidad mínima que pudiera fijarse, cuando, por razón de festividades, vacaciones estacionales o desplazamientos masivos de vehículos, se prevean elevadas intensidades de tráfico, o cuando las condiciones en que ordinariamente se desarrolle aquél lo hagan necesario o conveniente.

Por último y por razones de seguridad podrán establecerse restricciones temporales o permanentes a la circulación de vehículos en los que su propia peligrosidad o la de su carga aconsejen su alejamiento de núcleos urbanos, de zonas ambientalmente sensibles o de tramos singulares como puentes o túneles, o su tránsito fuera de horas de gran intensidad de circulación.

\section{B.- Lagos de Covadona (Principado de Asturias).}

Con base en este régimen jurídico se establecen limitaciones de acceso con vehículos a motor en los Lagos de Covadonga de acuerdo con un plan de acceso aprobado por el Principado de Asturias en el que ha participado la Asociación de Empresarios de los Picos de Europa (INCATUR). Actualmente, el plan de acceso a Covadonga prohíbe la utilización del vehículo privado en la carretera CO-4 durante el verano (entre el uno de julio y el 15 de septiembre), la Semana Santa y los principales puentes festivos del año. Durante estas fechas, la carretera que conduce a los famosos lagos está cerrada al tráfico privado entre las ocho de la mañana y las ocho de la tarde, por lo que en horario diurno solo es posible llegar al destino en transporte público. El resto del año el acceso en coches particulares es totalmente libre a cualquier hora de la jornada.

\section{C.- Península de Formentor (Mallorca).}

Por su parte la carretera del Faro de Formentor (Mallorca) también sufre restricciones de tráfico entre las 10:00 hs y las 19:00 hs de todos los días comprendidos entre el 9 de julio de 2018 y el 31 de agosto siguiente ${ }^{19}$. En efecto y de acuerdo con la resolución del Jefe Provincial de Tráfico en Baleares durante estas fechas y esta franja horaria, no se puede acceder al faro de Formentor más que en transporte público ${ }^{20}$.

\footnotetext{
${ }^{19}$ Entre los puntos kilométricos 8,700 y 19,600 de la carretera Ma-2210.

${ }^{20}$ La Resolución contempla una serie de excepciones a la limitación: vehículos de residentes o de propietarios de viviendas en la zona afectada por las medidas especiales de circulación, vehículos de
} 
Esta limitación se fundamenta en razones medio ambientales y sus objetivos consisten en reducir el número de vehículos a motor que visitan el Faro de Formentor, reducir los atascos de tráfico en la península de Formentor, evitar posibles accidentes de tráfico por la masificación de vehículos a motor, reducir la contaminación y ruidos que producen los vehículos, así como dar un servicio de transporte público a los visitantes para acceder a las calas y al faro.

\section{2.- Sistema de cupos de visitantes.}

Un segundo mecanismo que limita la presencia de visitantes y turistas en determinadas zonas consiste en el establecimiento de un sistema de cupo diario.

Tal es el caso de la Playa lucense de Las Catedrales (Ribadeo), que cuenta con un sistema de autorización para su acceso y visita, a través de una página web, que únicamente habilita 4.812 visitas diarias en Semana Santa y de julio a septiembre. Esta restricción se fundamenta en el problema de saturación que viene sufriendo en los últimos tiempos el arenal gallego, que puede suponer un riesgo para una zona que, además del turístico, tiene un gran interés natural. El objetivo de la Administración autonómica consiste en preservar el paisaje, combinar su aprovechamiento turístico y medioambiental, promocionar los medios de transporte alternativo y fomentar el conocimiento de su biodiversidad, entre otras.

En aplicación de la Ley 9/2001, de Conservación de la Naturaleza, quien ignore el veto y decida transitar por las sendas peatonales existentes podrá ser sancionado con multas de 600 a 6.000 euros. La medida supone atender las recomendaciones de geólogos y expertos de la Universidad de La Coruña, que coinciden en advertir que la parte superior de los acantilados de Las Catedrales son un espacio especialmente sensible, con hábitats prioritarios en la Unión Europea que hasta ahora sistemáticamente eran pisoteados por miles de visitantes. Además, con ello se degradaba el manto vegetal, propiciando las filtraciones de aguas pluviales que erosionaban cuevas, grutas, cornisas y salientes, provocando desprendimientos.

No muy distinto es el caso de las Islas Cíes, en la misma Comunidad Autónoma de Galicia. Por razones medio ambientales y de saturación turística, fundamentalmente embarcaciones, el Plan rector de usos y gestión del Parque Nacional Marítimo-Terrestre das Illas Atlánticas de Galicia establece un cupo de visitantes para la isla de Ons (1.800 personas por día) y las Islas Cíes (2.800 visitantes diarios).

La limitación del acceso a la Isla de Ons ha sido una consecuencia obligada después de la limitación a las Islas Cíes, por cuanto la primera se convirtió en la alternativa libre a las restricciones a las Cíes, desplazando la saturación de unas islas a otras.

En las Islas Canarias sucede otro tanto con la Isla de Lobos, considerada Parque Natural y en la que el Plan Rector de Uso y Gestión limita a 200 el número de visitantes, al tiempo que prohíbe la realización de acampadas.

transporte público gestionados por la Comunidad Autónoma, vehículos de salvamento, sanitarios, protección civil, emergencias y cuerpos de seguridad, vehículos de titularidad de la planta desaladora, vehículos de reparto de mercancías, de mantenimiento o de servicios técnicos, vehículos de la Autoridad Portuaria y del mantenimiento del faro, vehículos que transporten personas con movilidad reducida y bicicletas. 
De manera más específica existen restricciones y cupos para el acceso a la Cueva de Altamira, donde el Patronato del Museo Nacional y Centro de Investigación de Altamira hace suyas las recomendaciones de la Comisión de Seguimiento del Plan de Conservación Preventiva de la cueva y mantiene las visitas a la misma de manera controlada y limitada con el acceso de cinco personas y dos guías a la semana. En este sentido y aunque la causa principal del deterioro de las pinturas consiste en ela infiltración de agua por lavado, la presencia de personas (emisión de CO2) ha contribuido al deterioro por cuanto la cueva ha estado recibiendo 30.000 personas al año en 1952, 60.000 en 1957, y hasta 175.000 en 1973, debiendo restar cerrada al público entre 2002 y 2005.

\section{V.- CONCLUSIONES}

De todo lo anterior se colige que el turismo de masas es una realidad constatada, fruto de un crecimiento caótico, explicado por las plataformas colaborativas e internet, y en definitiva asociado a una profunda transformación del modelo turístico tradicional de alojamiento hotelero y extra hotelero.

La intervención administrativa, que -desde la sustitución de la técnica autorizatoria por la declaración responsable- parecía que había replegado la intensidad de la intervención administrativa, ha desplegado todo un elenco de medidas (urbanísticas y territoriales, tributarias y limitaciones ad hoc) al objeto de restringir el acceso de turistas y visitantes a determinados espacios públicos.

La problemática jurídica que encierran estas medidas consiste en cómo conciliar el uso público general del dominio público con las limitaciones, y la explicación no puede ser otra que la motivación y justificación de otros bienes más dignos de protección, como son el medio ambiente, la seguridad, la conservación de la naturaleza y del patrimonio histórico, entre otros.

En este sentido los instrumentos de ordenación del territorio (planes directores sectoriales) en materia de turismo establecen el concepto de capacidad de carga, vinculado a la densidad de población, y capacidad de acogida en función de la disponibilidad de recursos e infraestructuras, que lógicamente limitan el crecimiento de la población visitante.

Por su parte las medidas tributarias también modulan la demanda turística. Así, los impuestos sobre estancias turísticas en Baleares y Cataluña tienen una función principalmente recaudatoria, si bien al mismo tiempo afectan al juego de la oferta y la demanda de servicios turísticos, sin que ello suponga -como ha afirmado la jurisprudencia- doble imposición con el IVA.

Por último existen limitaciones específicas, ya sea del acceso a determinados espacios de vehículos a motor por razones ambientales y de contaminación, o el establecimiento de sistemas de cupos de visitantes a determinados espacios públicos, todo ello debidamente motivado en cuestiones de índole ambiental, paisajístico, preservación de recursos naturales...

En cualquier caso se constata un dinamismo notable, de manera que es la Administración de nuevo la que reacciona a los avances socio-económicos, hasta el punto de que tanto la dinámica del mercado turístico como la intervención 
administrativa se encuentran muy lejos de gozar de estabilidad. Urge en consecuencia determinar con claridad el modelo de territorio turístico que la Administración -con un innegable participación ciudadana- pretende, al objeto de evitar la peligrosa improvisación o decisiones cambiantes.

\section{VI.- BIBLIOGRAFÍA}

BAUZÁ MARTORELL, F. J. $<<$ Planeamiento urbanístico y turismo. A propósito de la zonificación del alquiler turística $>>$ Práctica Urbanística núm. $\mathrm{n}^{\circ}$ 152, mayo-junio 2018, No 152, 1 de mayo de 2018, Editorial Wolters Kluwer.

BAUZÁ MARTORELL, F. J. <<Intervención administrativa en la vivienda turística vacacional >> Revista Española de Derecho Administrativo núm. 189. 2018, pp. 313346.

BAUZÁ MARTORELL, F. J. <<Big data y open data en la administración turística: acceso y reutilización de información $>>$ Revista Vasca de Administración Pública núm. 108 (mayo-agosto), 2017, pp. 19-41.

BLASCO ESTEVE, A. $<<$ La planificación territorial de las zonas turísticas en España $>>$ Revista de Derecho Urbanístico y medio ambiente núm. 262. Diciembre 2010.

BOUAZZA ARIÑO, O. - BASSOLS COMÀ, M. Planificación turística autonómica. Reus. Barcelona, 2007.

E/CNMC/003/18 Estudio sobre la regulación de las viviendas de uso turístico en España. 19 de julio de 2018.

DE LA ENCARNACIÓN, A. M. <<El alojamiento colaborativo: Viviendas de uso turístico y plataformas virtuales $>>$ Revista de Estudios de la Administración Local y Autonómica núm. 5. Enero-junio 2016.

FERNÁNDEZ, T. R. $<<$ El desconcertante presente y el imprevisible y preocupante futuro del Derecho urbanístico español>> Revista Española de Derecho Administrativo núm. 94. 1997, pp. 189-201.

FERNÁNDEZ GONZÁLEZ, C. El impuesto balear de estancias turísticas. Lleonard Muntaner, editor. Palma, 2017.

GARCÍA CALVENTE, Y. "Régimen tributario del turismo colaborativo" en GOSÁLBER PEQUEÑO, H. (Dir.) El régimen jurídico del turismo colaborativo. Wolters Kluwer. Madrid, 2019.

NAVARRO JURADO, E. ¿Puede seguir creciendo la Costa del Sol? Indicadores de saturación de un destino turístico, Colección Monografías, Servicio de Publicaciones de la Diputación de Málaga, 2003. 
SALOM PARETS, A. <<La capacidad de carga "conditio iuris" en la normativa territorial y turística>> Revista de Derecho Urbanístico y medio ambiente núm. 313. Abril-mayo 2017, pp. 39- 63.

SOCÍAS CAMACHO, J. $<<$ Un problema actual de la vivienda: uso residencial versus uso turístico>> Revista de Derecho Urbanístico y medio ambiente núm. 317. Noviembre 2017, pp. 17- 47.

ZAMORA ROSELLÓ, M. R. $<<$ La sostenibilidad turística a través de los instrumentos andaluces de planificación>>> Revista Andaluza de Administración Pública núm. 98, 2017, pp. 395-426.

ZAMORA ROSELLO, M. R. "La Ordenación de los recursos turísticos”, en FWERNÁNDEZ RAMOS, S. - PÉREZ MONGUIÓ, J. M. - PRADOS PRADOS, S. Estudios sobre el derecho andaluz del turismo. Junta de Andalucía. Sevilla, 2008. 